\title{
Moral Imagination And Ethics For The Accounting Professional
}

Lawrence M. Metzger, (Email: lmetzge@luc.edu), Loyola University, Chicago

"The patron of calling which involves the use of highly technical knowledge, since s/he is not qualified to judge the worth of the services s/he receives, is in a position of extreme dependence and requires assurance of the trustworthiness of the practitioners s/he uses." Edward Ross, 1916

\begin{abstract}
The accounting professional, whether s/he be in the private or public sector, faces many situations in his/her day-to-day activities that require thoughts and actions that have ethical overtones. One needs only look at the Enron situation to verify this idea. While the accounting profession has long had established codes of ethical conduct, these codes are by no means the be all and end all of ethical decision-making. So while accounting professionals can certainly refer to and use the relevant code of ethics for a particular situation, it is clear that these by themselves are not usually sufficient in depth and detail to solve all but the most straightforward, if there is such a thing, situations. To address most ethical situations calls for thinking far beyond the tenets of a code of ethics. It requires significant intellectual capacities and specific skills. Specifically, it requires moral imagination.
\end{abstract}

A general definition of moral imagination comes from Mark Johnson: "Moral imagination is the ability to imaginatively discern various possibilities for acting within a given situation to envision the potential help and harm that are likely to result from a given action." From a business perspective moral imagination "is the ability to perceive that a web of competing economic relationships is, at the same time, a web of moral or ethical relationships." (Archie Carroll). Moral imagination integrates common morality into decision processes and moral judgment, anticipates consequences, and projects new practical solutions that take into account a variety of points of view and respond to or even create moral demands.

The question addressed in this paper is: How can accounting professionals become moral imaginers? The main focus of this paper is to show that one way to develop moral imagination is to begin to learn and think metaphorically. The concept of metaphoric thinking is examined within the context of an accounting professional's moral bearing to demonstrate how these thought processes can help in moral and ethical decisions.

\section{Introduction}

onsider the following hypothetical situation: Yukon Mining Company extracts and processes a variety of ores and minerals. One of its operations is a coal cleaning plant that produces toxic wastes. For many years the wastes have been properly disposed of through National Disposal, a company experienced in disposing such items. However, disposal of the toxic wastes was becoming an economic hardship because increasing government regulations had caused the cost of such disposal to quadruple in the last six years.

Readers with comments or questions are encouraged to contact the author via email. 
Rebecca Long, Director of Financial Reporting for Yukon Mining, was preparing the company's financial statements for the year ended December 31, 2001. In researching the material needed for preparing a footnote on environmental contingencies, Rebecca found the following note scribbled in pencil at the bottom of a memo to the general manager of the coal cleaning plant. The body of the memo gave details on the increases in the cost of toxic waste disposals:

"Ralph, We've got to keep these cost down or we won't meet budget. Can we mix more of these wastes with the shipments of refuse to the Oak landfill? Nobody seems to notice that coal-cleaning fluids when we mix it in well. Rebecca was bothered by the memo. She considered ignoring it, pretending that she had not seen it. But after a couple of hours, her conscience would not let her do it. Therefore she pondered what to do.

\section{The Responsibilities Of Accountants}

The task of the accounting professional is, not surprisingly, to give an account. That is, s/he provides information to various stakeholders, both inside and outside the firm that is used for analysis and decision-making. But this is not an easy task. Accounting information is complex and requires great skill and knowledge to prepare this information. Users rely on accountants to prepare the data in a proper relevant and reliable manner.

Along with complexity there is also a real softness, i.e., estimates, assumptions, and alternative reporting principles, to accounting information. Accounting professionals know this, as do most managers. Indeed, it is the softness of accounting numbers that is the reason why managers are so interested in them. I. C. Stewart (1990) stated: "It seems to be widely accepted today that managers, far from presenting a true and fair view of their corporations' operations and financial positions, choose those accounting procedures that will maximize their own self-interest." Accounting numbers can be and in fact are manipulated by management when there is perceived motivation to do so. The highly publicized Enron situation is just the most recent case of stretching accounting rules to try to manipulate investors and fool the market.

\section{Accounting Codes Of Ethics}

There are several codes of ethical conduct that are in place within the accounting profession. Codes have been developed (among others) by the American Institute of CPAs, which primarily covers duties and responsibilities of professionals working in the assurance (audit) area, the Institute of Management Accountants, whose code covers responsibilities in the corporate sector, the Institute of Internal Auditors, covering the responsibilities of those professionals working in the internal audit function, and the Association of Government Accountants, covering accounting professionals working in the public sector..

While there is no doubt that these codes are helpful guides for helping the accounting professional in coping with ethical situations, they are by no means the be all and end all of ethical decision making. They are guides and nothing more than this. As far back as 1907, Joseph Sterrett in his paper titled "Professional Ethics" stated: “...let us first divest ourselves of the thought that any system of professional ethics for accountancy...can or should supercede or even modify those fundamental principles of right and wrong." Second, he noted "that ethical standards were not absolute; they were evolutionary and therefore rules incorporated into any formal code of ethics must change over time."

\section{Moving Beyond Ethics Codes}

While accounting professionals can certainly use and gain from the use of relevant code of ethics, it is clear that these by themselves are not usually sufficient in depth and detail to solve all but the most straightforward, if there is such a thing, situations. To address most ethical situations calls for thinking far beyond the basic tenets of a code of ethics. It requires significant intellectual capacities and specific skills. This paper intends to show that ethical decision-making requires the development and use of a person's moral imagination, especially as it applies to using metaphors to help in ethical decision-making. 


\section{Moral Imagination}

The concept of moral imagination goes as far back as Adam Smith. In his book, The Theory of Moral Sentiments, he links imagination and sympathy. He states "Sympathy and imagination are necessary for moral judgment because in judging intentions or actions one must first understand what another feels, or, engage in imaginative self-evaluation on ones own emotions that accompany the intention or action... Moral imagination is the ability to empathize, to understand another point of view, and be creative in ethical decision making."

Moving to more current times, moral imagination has been defined in a multitude of ways by various authors. Martin Price (1983) defines moral imagination as recognizing the complexities of decision-making and the effect or release involved in solving or ignoring or evading problems. Mark Johnson (1993) defines moral imagination an as ability to imaginatively discern various possibilities for acting within a given situation and to envision the potential help and harm that are likely to result from a given action.

Charles Larmore (1981) refers to moral imagination as our ability to elaborate and appraise different courses of action that are only partially determined by a given context of moral rules, in order to learn what in a particular situation is the morally best thing to do. Moral imagination thus provides far greater evidence of an intrinsic interest in what is morally right than does merely the observance of moral rules. Tierney (1994) states: "Without an imagination specifically devoted to seeking out ethically significant aspects, ethical discernment would flounder, particularly in complex cases....Imagination is a means of ethical understanding, an essential and irreducible means by which individuals come to make the foundational distinctions which constitute the structure of their ethical interpretations."

Archie Carroll (1987) frames moral imagination within a business perspective when he says moral imagination is: "The ability to perceive that a web of competing economic relationships is, at the same time, a web of moral or ethical relationships." Werhane (1998) believes that developing moral imagination involves heightened awareness of contextual moral dilemmas and their mental models that create new possibilities, and the capability to reframe the dilemma and create new solutions in ways that are novel, economically viable, and morally justifiable.

Moral imagination can contribute to each step in ethical decision-making process. Moral imagination enables one to critique the situation at hand and evaluate newly formulated possibilities and justification of possibilities outside a given script or a defined role. Moral imagination can move ones thinking from the status quo to new possibilities and then evaluating those possibilities by some norm. Moral imagination can also enable creative thinking about how to revise common precepts of morality set forth by a particular group.

\section{The Nature Of Ethical Reasoning In Business}

LaRue Hosmer (1991) offers five major characteristics of ethical problems that also show the complexity of managerial ethics and point out the nature of ethical reasoning:

1. Most ethical decisions have extended consequences. Managerial decisions, actions, and results have consequences whose effects extend beyond their control and organization into society. For example, bribes change governmental processes. The consequences and effects should be considered before decisions are made.

2. Most ethical decisions have multiple alternatives. Simple "yes" or "no" choices do not adequately characterize the many alternatives that exist and that should be considered in such decisions as "Should a manager pay a bribe?" or "Should a factory pollute the air?"

3. Most ethical decisions have mixed decisions. As in the second point, outcomes and alternatives are not unambiguous; they have social benefits and costs as well as financial revenues and expenses associated with ethical choices. 
4. Most ethical decisions have uncertain consequences. Unanticipated and unknown consequences can follow ethical choices.

5. Most ethical decisions have personal implications. Such decisions can affect the lives and careers of the decision makers. Individual costs and benefits, in addition to financial and social ones, are associated with most alternatives in ethical decisions.

\section{Decision-Making Theory: Action Selection}

We often speak as though the decision-maker has some set of potential plans of action (options) and that decision-making consists of choosing the best among them. However, consider your own decision making-you frequently have no idea about what might be reasonable plans of action. Often, you start off in one direction only to change your mind when things go awry. In fact, decisions seldom are made at a single point. Rather the process seems to feel its way along, changing in the light of feedback and often leading in directions that were never conceived of when it all began.

The "feeling along" nature of decision making is very difficult to describe in a tractable theory. It is far easier to talk as though decision options, especially ethical decisions, actually exist in full-blown clarity and that the choice among them occurs at a single point in time. But this is merely a useful fiction.

Deciding how to act in a particular set of circumstances will depend on how we frame the situation. This is a matter of determining what is important in the situation. It is very much a matter of reading situations, character and intentions. Martha Nussbaum (1986) says... "Moral knowledge ... is not simply intellectual grasp of propositions; it is not even simply intellectual grasp of particular facts, it is perception. It is seeing a complex concrete reality in a highly lucid and richly responsive way; it is taking in what is there, with imagination and feeling."

\section{Help In Moral Decision-Making}

In ethics, because it deals with practice rather than observations, a problem occurs. When we attempt to bring moral abstract theory to bear on concrete situations, we often find ourselves faced with a dilemma: the more precise and comprehensive our theory of the principles involved in concrete situations of choice and decision, and the more thorough our characterization of the reasons why these principles should be followed, the less relevant and applicable our theory becomes, both to the exigencies of the situation and to the actual motivations of the persons involved (Tierney, 1994).

\section{Imaginative Schemas}

According t Johnson (1993) our moral understanding depends in large measures on various structures of the imagination: These structures include: prototypes, images, image schemas, metaphors, and narratives. This paper focuses primarily on one of these structures, metaphors. This discussion will ultimately ask the question: How can accounting professionals become better "moral imaginers?"

\section{Metaphors}

A metaphor is a term or phrase that is applied to another unrelated term or phrase to create a nontraditional relationship. "All the world is a stage." and "Life is a journey." are two famous metaphors.

Metaphor is one of the principle mechanisms of imaginative thinking. Metaphor is essential to our moral understanding at two basic levels: (1) Our most important moral concepts (e.g. will, action, purpose, rights, duties, laws) are defined by systems of metaphors and (2) We understand morally problematic situations via conventional metaphorical mappings. Morality therefore is metaphoric and imaginative. 
Metaphors are the folk theories of morality (Johnson, 1993). Metaphors are imaginative structures that make criticism possible. They give us alternative viewpoints and concepts from which to evaluate the merits of a moral position. They make it possible for us to envision the probable consequences of a proposed course of action, such as how other people are likely to be affected, how it might change our relationships, and what new possibilities it might open up (or close off) concerning how we can grow.

According to Kierney (1994), the key distinction for a theory of imagination is not between the real and unreal, but between the literal and metaphorical. Imagination is a doing which is a seeing. To imagine is to make certain kinds of interpretative distinctions in one's world, and this is a cognitive activity. He goes on to say that the greatest thing of all by far is to be master of metaphor. It is the one thing that cannot be learnt from others, and it is also a sign of genius, since a good metaphor implies an intuitive perception of the similarity of dissimilars.

Metaphors make criticism possible, for they give us alternative viewpoints and concepts from which to evaluate the merits of a particular moral position, and make it possible for us to envision the probable consequences of a proposed course of action. It is principally metaphorical reasoning that makes it possible for us to learn from our experience. Such reasoning is necessary if we are to draw out the implications of our previous experience for a present situation. We must be able to project beyond clear cases to those that are completely novel.

Metaphor enters our moral deliberation in four ways (Johnson, 1993):

- $\quad$ It gives rise to different ways of conceptualizing situations.

- $\quad$ It provides different ways of understanding the nature of morality.

- It provides a basis for analogizing and moving beyond the clear or prototypical cases to new cases.

- It gives us constrained ways to pursue these metaphorical extensions. It thus allows us to learn from experience so as to grow in our moral understanding.

\section{Accountants As Moral Imaginers}

Metaphors help in unpacking the ethical content of a given situation. Metaphors build upon one another to form vast, interconnected systems. So how does an accounting professional start to use metaphorical thinking for ethical decision-making?

According to Johnson (1993), every moral concept that is any way connected to action turns out to be metaphorical. This includes our conceptions of will, rights, duties, obligations, moral debt and moral credit. The concepts of rights and duties can be defined by what can be called the social accounting metaphor. Causation can be thought of as a commercial transaction. In this type of metaphor, well-being is considered wealth. Well-being is understood metaphorically as the possession of many valuable commodities. And an exchange for value metaphor says that an object, actual or metaphorical, is worth what someone is willing to give in exchange for it, either in terms of other commodities or money.

The social domain can be evaluated metaphorically in terms of financial concepts. For example, according to the social accounting metaphor, having a right is having a letter of credit (IOU) that gives you access to a desired object (which is an action you can perform or a state you can be in). Where you have a right to such a desirable action, other people have a duty not to block your access to that object. They have a debt to you, which you have a right to collect on. They owe you whatever you have a right to.

From the perspective of an accounting professional, the social accounting metaphor sets up a framework in which the accountant has rights and duties. It helps define what it is to have rights and duties, in terms of language and thought processes that accounting professionals are trained to understand and use.

Johnson extends this model to what he calls the moral accounting metaphor. Within the moral accounting metaphor, well being is understood as wealth, so that doing something that increases the well being of another is a moral act understood via metaphor as giving her/him a commodity that increases her wealth. Moral interactions are 
viewed metaphorically as commodity transactions. This metaphor constitutes our primary conception of the way in which people can accumulate moral credit and moral debt.

The moral accounting metaphor is shown below:

\section{Commodity Transactions}

Objects, commodities

Utility or value of objects

Wealth

Accumulation of goods

Unprofitable: causing decrease in wealth

Money (as a surrogate for goods)

Giving/taking money or commodities

Account of transactions

Balance of accounts

Debt

Credit

Fair exchange/payment

\section{Moral Interaction}

Deeds (actions) states

Moral worth of actions

Well-being

Moral: causing increase in well-being

Immoral: causing decrease in well-being

Well-being

Performing moral/immoral deeds

Moral account

Moral balance of deeds

Moral debt $=$ owing something good to another

Moral credits $=$ others owe you something

Justice

The moral accounting metaphor constitutes our primary conception of the way in which people can accumulate moral credit and moral debt. Such schemas do not, in themselves define "good" and "bad". Instead they give us the primary structure for forms of reasoning about what we owe others and what we are owed by others for our actions. Such forms of moral reasoning exist only by virtue of a metaphor system.

\section{Applying The Moral Accounting Metaphor}

Refer back to the situation at the beginning of the paper. We will look at this case from the point of view of Rebecca. We could of course also view this situation from the point of view of the other two employees. But let us see how Rebecca can us the moral accounting metaphor model to help her morally imagine the possibilities for her decision.

\section{Objects, Commodities --------:----------Deeds, (Actions) States}

Accounting is often viewed metaphorically as the language of business. Accounting takes data and transforms it into information to be used for analysis and decision-making. Information can be thought of metaphorically as a commodity. In this case the information is that two employees may possibly collude to mix toxic waste with other waste product to reduce costs. Rebecca has two basic actions to choose from in this case. She can do nothing or report the incident. She can imaginatively see that reporting this information is equivalent of providing a product or commodity that benefits both the company and the public good.

\section{Utility Or Value Of Objects---:--:------Moral Worth Of Actions}

Rebecca can view her actions as a measure of moral worth. Doing nothing provides no value or utility to either the firm or the other stakeholders. The two employees involved in this situation are acting without management approval. Indeed, it can be argued that management would want nothing to do with this sort of action. Bringing this situation to management's attention could provide two types of value added information. The first of course is the reporting of the action of mixing the waste together. The second piece of value-added information would be that management may want to look at its budgeting policies and see whether or not these policies indirectly encouraged this action on the part of the two employees who would argue they were trying to meet budget expectations. 


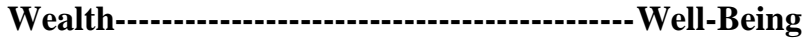

By recognizing, through her imagination, the situation as one that could be very detrimental to the well being of the firm and all stakeholders, Rebecca can help increase the wealth of the firm by making sure that this dumping of toxic waster does not take place.

Accumulation of goods

Profitable $=$ causing increase in wealth

Unprofitable $=$ causing decrease in wealth

Money (as surrogate for goods)

Giving/taking money or commodities
Increase in well-being

Moral = causing increase in well-being

Immoral $=$ causing decrease in well-being

Well-being

Performing moral/immoral deeds

In this case Rebecca needs to realize that the increase in well-being refers to the well being of the firm. The accumulation of goods can be though of as increasing or decreasing the level of goodwill of the firm. Properly disposing of the toxic waste will provide goodwill for the firm in that it will be perceived as being environmentally responsible. Over time goodwill could ultimately have the effect of increasing profits (making money). If on the other hand it is discovered that the process of combining these waste materials is occurring, the company will receive negative publicity from the market place and in all probability come under scrutiny of various government agencies. Over time this action could lead to a decrease in well-being and prove very unprofitable (losing money) for the firm.

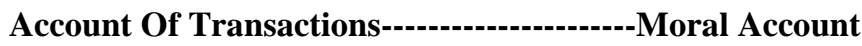

As mentioned in the introduction, the task of the accounting professional is to give an account. The accountant provides information to various stakeholders, both inside and outside the firm that is used for analysis and decision-making. Accounting information appears to be rigorous and determinate when in fact it is not. Accounting systems do account for transactions but it is not always clear what a transaction is or when it should be recorded. Giving a moral account of oneself can be thought of metaphorically as giving an account of the financial activities of the firm. Rebecca can ask of herself: Am I giving a good account of myself with respect to the decision I make? She can also ask: If I choose to do nothing, will the firm be giving a proper account of itself?

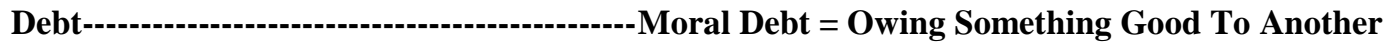

Rebecca should see that she has a moral debt to all the stakeholders of the firm along with the general public to make sure that this illegal toxic waste disposal does not occur. She owes something good, i.e., the stopping of this practice. Using the basic accounting concept that all transactions must balance, Rebecca has incurred a debt (expense) and a liability (obligation) to report this situation to firm management.

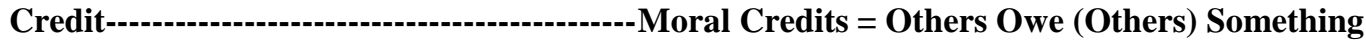

If Rebecca has any hesitation about reporting this situation she could ask herself what these two employees actually owe her and the firm. While their actions might provide some short run cost savings, Rebecca should recognize that these employees have a moral debt to the firm and they owe all the stakeholders proper disposal of the waste.

\section{Fair Exchange/Payment----------------------Justice}

Rebecca is an employee of the firm. As such she receives payment for her services. As part of the fair exchange of her efforts on behalf of the firm for payment, she should recognize that the proper disposal of the toxic waste is in a broad sense a matter of justice. Justice in this sense is balancing the goals of the firm (profitability) and the goals of society as a whole (a good place to live). 


\section{Conclusion}

Organizations do not make decisions, individuals do, and when they do they must take others into account. Accounting professionals can in a sense be the moral conscience of a firm. They can evaluate and present information for decision-making with a detached view. By making a moral commitment toward their own actions and expanding their thought processes with the use of imaginative tools such as metaphorically thinking, accounting professionals can provide great benefits to both the organization they work for and the community at large.

\section{References}

1. Carroll, Archie, "In Search of the Moral Manager", Business Horizons, 30: 1987, 7-25.

2. Horngren, Sundem and Stratton, Introduction to Management Accounting., $12^{\text {th }}$ edition. Prentice Hall, 2002.

3. Hosmer, LaRue T, The Ethics of Management, Irwin Publishing, Homewood, IL 1991.

4. Johnson, Mark, Moral Imagination, Implications of Cognitive Science for Ethics, The University of Chicago Press, 1993.

5. $\quad$ Larmore, Charles, "Moral Judgment", Review of Metaphysics, 35: 1981, 275-296.

6. $\quad$ Nussbaum, Martha, The Fragility of Goodness, Cambridge University Press, 1986.

7. Price, Martin,. Forms of Life: Character and Moral Imagination in the Novel, Yale University Press, 1983.

8. Stewart, I.C., "Accounting and Accountability: Double Entry, Double nature, Double Identity," Crux 26, no.2 (June 1990, p. 13-20)

9. Tierney, Nathan, Imagination and Ethical Ideals, State University of New York Press, 1994.

10. Werhane, Patricia H., Moral Imagination and Management Decision Making, Oxford University Press, 1999.

Notes 